\section{International Journal of \\ Astrobiology}

\section{cambridge.org/ija}

\section{Research Article}

Cite this article: Nascimento-Dias $\mathrm{BL}$, Zucolotto ME, Belgo HC, da Silva TVF, Anjos VdeC (2020). Detection of organic or inorganic material in Martian meteorite Zagami by vibrational spectroscopy? International Journal of Astrobiology 19, 438-445. https://doi.org/ $10.1017 / \mathrm{S} 147355042000021 \mathrm{X}$

Received: 14 June 2020

Revised: 27 July 2020

Accepted: 7 August 2020

First published online: 14 September 2020

Key words:

FTIR; Mars; Raman; Zagami meteorite

Author for correspondence:

Bruno Leonardo do Nascimento-Dias,

E-mail: bruno.astrobio@gmail.com (c) The Author(s), 2020. Published by Cambridge University Press

\title{
Detection of organic or inorganic material in Martian meteorite Zagami by vibrational spectroscopy?
}

\author{
Bruno Leonardo do Nascimento-Dias ${ }^{1}$ (D), Maria Elizabeth Zucolotto², \\ Hugo Camarano Belgo ${ }^{1,3}$, Talita Valverde Ferreira da Silva ${ }^{3}$ and \\ Virgĩlio de Carvalho dos Anjos ${ }^{1}$
}

\footnotetext{
${ }^{1}$ Physics, Universidade Federal de Juiz de Fora, Juiz de Fora, Brazil; ${ }^{2}$ Geology, Universidade Federal do Rio de Janeiro Museu Nacional, Rio de Janeiro, Brazil and ${ }^{3}$ Chemistry, Universidade Federal de Juiz de Fora, Juiz de Fora, Brazil
}

\begin{abstract}
Zagami is a basaltic shergottite well characterized among Martian meteorites. For this reason, it is used as a reference sample to verify the feasibility of the vibrational spectroscopy techniques. In general, these techniques seeking extract spectral signatures from individual mineral present in the meteorite samples. Among some FTIR results were detected organic compounds in the Zagami meteorite and recorded in some articles. Based on these results, an analysis of a Zagami meteorite sample was performed using FTIR and Raman spectrometry. Examining the fragment of Zagami meteorite using the FTIR technique, it was possible to identify the same band of 2920 and $2850 \mathrm{~cm}^{-1}$ described by other references, which were interpreted as organic components and were recorded such as aliphatic hydrocarbon. Another unusual result in Martian meteorite was the detection of the $1300 \mathrm{~cm}^{-1}$ band using Raman. The main reason for this peculiarity is that band is characterized in meteorites as a D band. Generally, this band is attributed to structural defects and the disordering of carbon. However, care should be taken when interpreting Raman spectra around $1300 \mathrm{~cm}^{-1}$ and FTIR spectra $2950-2840 \mathrm{~cm}^{-1}$ of the sample from oxidizing environments such as Mars. Misconceptions can occur during the interpretations of the bands, and this can lead to incorrect identification. Thus, an analysis of the mentioned peaks, such as chemical and mineralogical assignments, will be provided and suggested in order to compare the results that mentioned the presence of organic compounds in the Zagami meteorite.
\end{abstract}

\section{Introduction}

Martian meteorites are considered important pieces of geological material from Mars. Although most of the geological records have been destroyed, as happened on Earth, the geological evolution of the Martian surface, its physical information and chemical characteristics can still be studied through the Martian meteorites (Nimmo and Tanaka, 2005). In general, Martian meteorites are divided into Shergottites, Nakhlites and Chassignites (SNC). The SNC meteorite group includes igneous rocks (basalts and cumulates) which generally contain evidence for shock impact metamorphism, such as glass veins and cracks.

Zagami meteorite is a very famous shergottite, and has been well studied (McCoy et al., 1999; Wang et al., 1999; Nyquist et al., 2001). Some of these studies detected organic compounds in the Zagami meteorite and recorded in some articles (Anderson et al., 2005; Palomba et al., 2006). Thus, one of the main intentions of this work is to analyse the spectral signature obtained by vibrational spectrometry and compare the result with spectral compositions of the same sample that reported the presence of organic compounds.

According to Anderson et al. (2005), infrared spectroscopy would be an obvious choice as part of an instrument for analysing Martian samples. In particular, the molecular bond information provided by vibrational spectrometry, such as Raman and FTIR, adds powerful interpretive information to methods that yield only elemental composition.

Finally, it can be said that this research conforms to the focal point for searching for traces of life in the Solar System, which is Mars. The main reason for this attribution to Mars is because of its geological similarity and proximity to Earth. Thus, information obtained from Martian meteorites may provide important implications for the study of life or habitability conditions that might have existed in the Solar System. However, it is worth noting that although there are results pointing to the existence of organic compounds in Martian meteorites, such as in Zagami meteorite, it is always necessary to carefully ascertain such attributions. 


\section{Materials and methods}

\section{Martian Zagami meteorite}

The Zagami meteorite fell on 3 October 1962 about $1.2 \mathrm{~km}$ from Zagami Rock, Katsina Province, Nigeria (Graham et al., 1985). In 1985 , the main mass of $18 \mathrm{~kg}$ was first sent to studies in the Geological Survey of Nigeria in Kaduna, but since 1988 when Robert Haag (meteorite dealer) obtained a large piece of the Zagami meteorite, it was cut and distributed widely. Zagami is a basaltic shergottite that with a crystallization age of $180 \mathrm{Ma}$ (e.g. Shih et al., 1982; Jones 1986; Nyquist et al., 2001) can be placed among the youngest SNC meteorites, considerably younger than the average Martian crust.

SNC ejection mechanism has been explained also for the most common near-normal impacts, for the crater of hundreds to few $\mathrm{km}$ in size (Vickery and Melosh, 1987; Carr and Head, 2010). The space exposure ages of Zagami suggest that it was ejected from the surface by the same impact event that launched Shergotty, Los Angeles and QUE94201 about 2.7-3.1 Ma ago (Eugster et al., 1997; Nyquist et al., 2001). In general, the sample Zagami meteorite in Fig. 1 analysed in this work (rectangular shape measuring about $1.0 \times 0.7 \times 0.2 \mathrm{~cm})$

Although Zagami meteorite is quite distinct petrologically and chemically from the rest of the basaltic achondrites, and Shergotty are texturally and mineralogically similar to terrestrial diabases, plagioclase has been shocked to maskelynite (Stolper and McSween, 1979). The meteorite is texturally heterogeneous, with several distinct lithologies dominated by the so-called Normal Zagami (NZ) lithology. In the NZ lithology, pyroxene crystals, with an average grain size $0.24-0.36 \mathrm{~mm}$, are arranged with maskelynite grains in a preferential orientation which gives the meteorite its characteristic foliation texture. The average mineral modal, for the NZ lithology, varies in the following intervals: pyroxene $70-80 \%$, maskelynite $10-25 \%$, minor phases $4-9 \%$ (e.g. Stolper and McSween, 1979; McCoy et al., 1999). In addition, some fine black glass veins apparently were formed by 'shear spillage during shock' (Langenhorst and Poirier, 2000), and could contain rare recent information on high-pressure phases.

The fragment of Zagami meteorite used for development in this work was provided by the Rio de Janeiro National Museum (UFRJ), which confirmed that the sample of Zagami meteorite corresponds to the mineralogy and textured description in Meteoritical Bulletin (Graham et al., 1985)

\section{FTIR}

In this work, Fourier transform infrared (FTIR) spectrometer was used (Alpha II, Bruker Optics, Ettlingen, Germany). The spectra of the sample were collected under environmental conditions in the range between 4000 and $400 \mathrm{~cm}^{-1}$, with a resolution of 4 $\mathrm{cm}^{-1}$ and acquiring an average of 128 scans. In addition, Hyperion 3000-VORTEX 70 was used. This equipment has a diamond attenuated total reflectance (ATR) accessory and OPUS software (v. 6.5, Bruker Optics) was used for instrumental control and for spectral acquisition.

The analysis of the Martian meteorite fragment followed some procedures/protocols, which will be listed and explained. First, a tablet containing only potassium bromide $(\mathrm{KBr})$ was prepared. This type of material has a $100 \%$ transmission window in the range of the number of waves $\left(4000-400 \mathrm{~cm}^{-1}\right)$ for FTIR.

Based on this, a measure was taken to obtain the infrared spectrum of the $\mathrm{KBr}$ chip only. The purpose of this measure is to

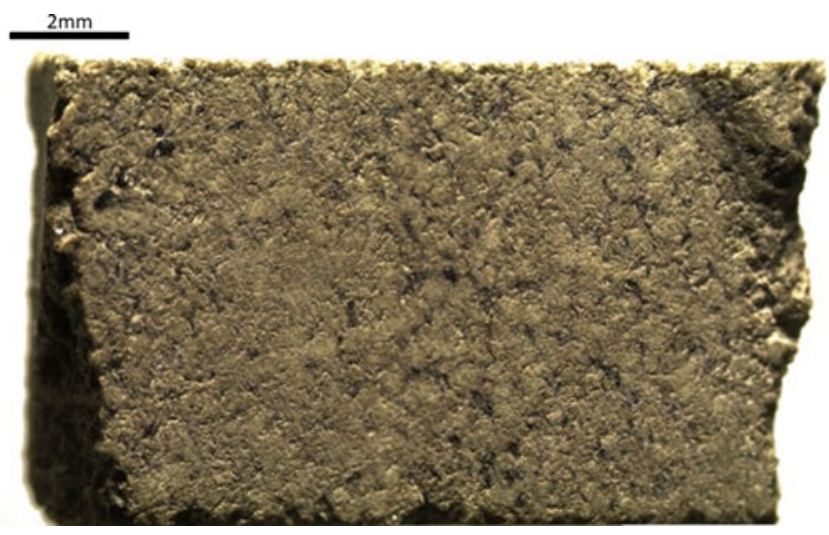

Fig. 1. Fragment of Martian meteorite Zagami used in this work.

remove any negative contribution or impurity that may be present in the device or in the $\mathrm{KBr}$ used. Thus, the results obtained containing the analyte disregard these possible contributions during the measurements. Potassium bromide, in this case, acts as a kind of what can be called 'white' or 'background'. Subsequently, all this information will be subtracted from the final spectrum.

The published article database was used to compare the result obtained with that of the reference as an analysis method such as Palomba et al. (2006), Brolly et al. (2016), Lakshmi Reddy et al. (2015).

\section{$\mu$ Raman}

Data were obtained using the $\mu$ Raman Confocal Bruker Senterra equipment coupled to an Olympus microscope. (lenses $10 \times$, $20 \times, 50 \times$ and $100 \times$ ), available at UFJF Chemistry department. Measurements were made with the $50 \times$ objective lens. In addition, the system is equipped with 532, 633 and $785 \mathrm{~nm}$ excitation lasers, but in this work, a $633 \mathrm{~nm}$ laser was specifically used. The output power was $20 \mathrm{~mW}$ and integration time $10 \mathrm{~s}$, with a spectral resolution of $1 \mathrm{~cm}^{-1}$.

It is noteworthy that the limitations in the analyses performed lie in possible interference of fluorescence and Raman scattering of the object under consideration. Basically, this can cause a large noise in the spectrum, causing no Raman peaks or lowintensity peaks for some constituents.

\section{Results}

FTIR

Infrared (IR) spectra of the Martian Zagami meteorite were acquired in the mid-infrared (MIR) region (from 4000 to 400 $\mathrm{cm}^{-1}$ ). Although the FTIR technique is not commonly used to study minerals in meteorites, important information regarding sample composition can be obtained. Thus, the data obtained from the Chemistry department of UFJF of the Zagami meteorite will be presented below in Fig. 2 .

FTIR spectrum shows the bands in the higher wavelength region at 1642, 1742, 2850, 2920 and $3455 \mathrm{~cm}^{-1}$ and lower wavelength region at 500, 635, 672, 725, 880, 936, 962, 1050, 1344 and $1400 \mathrm{~cm}^{-1}$. Based on this result, a comparative analysis was performed between spectra in order to characterize and try to provide the chemical composition. 


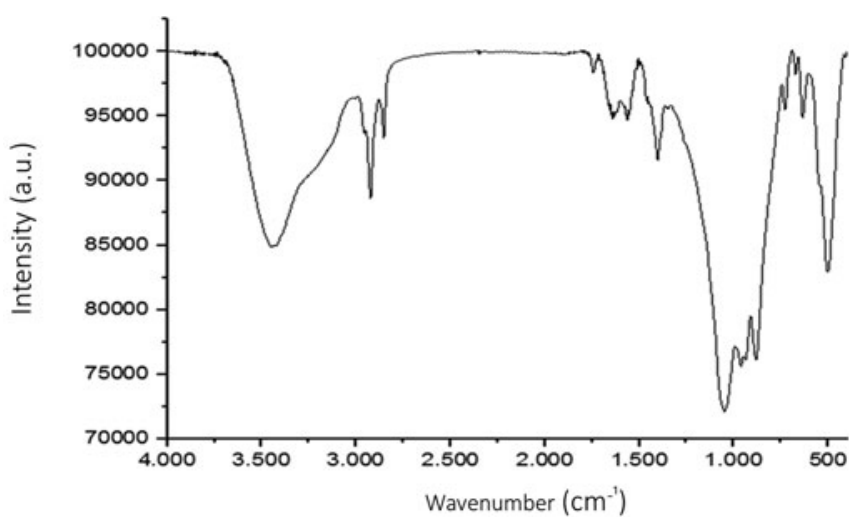

Fig. 2. FTIR spectrum obtained from the Martian meteorite fragment.

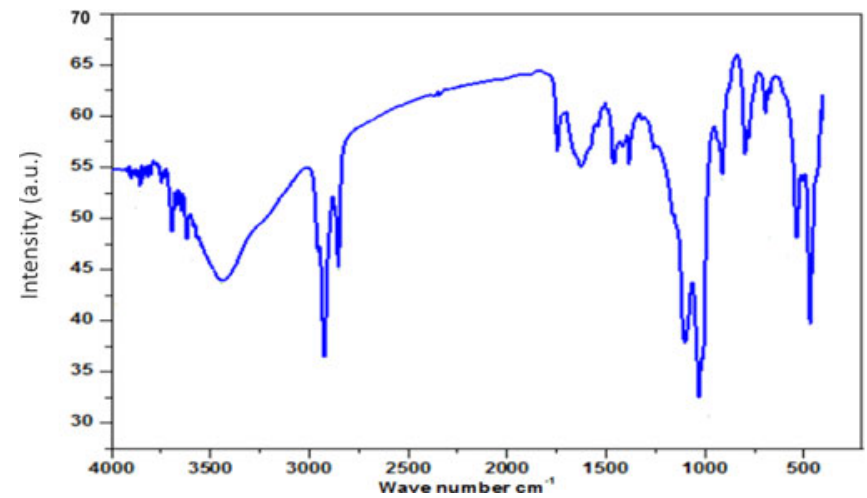

Fig. 3. Reference spectrum by Lakshmi Reddy et al. (2015) to compare with the result obtained.

The characterization of the chemical compound obtained from Zagami meteorite by IR was investigated and compared with the spectrum of Lakshmi Reddy et al. (2015) in Fig. 3. The reference spectra Cui et al. (2013) and Lakshmi Reddy et al. (2015) used to perform the comparative analysis with the spectrum obtained from the Zagami meteorite are described together with the spectrum of the fragment analysed in Table 1.

\section{$\mu$ Raman}

The analysis of the Martian Zagami meteorite was performed by varying the point position of the beam by sample regions. The Raman spectrum shows in Fig. 4 a composition of the frequencies 220, 290, 325, 400, 666, 1004 and $1328 \mathrm{~cm}^{-1}$.

For purposes of comparison and characterization of the obtained compound, spectra of terrestrial mineral samples were collected from literature sources or from the database cited in the text. The peak of the spectra is described and compared with two spectra of pure minerals used as references in Table 2.

Based on the comparison between the obtained data and the references, the iron oxide compound and the Hedenbergite mineral $\left(\mathrm{CaFe}^{+2} \mathrm{Si}_{2} \mathrm{O}_{6}\right)$ appear to be part of the Zagami meteorite sample. In addition, it is possible to attribute a possible intergrowth between both minerals because of how the spectra are mixed and overlapping some peaks such as $660 \mathrm{~cm}^{-1}$ (iron oxide) and $667 \mathrm{~cm}^{-1}$ (Hedenbergite) or $1005 \mathrm{~cm}^{-1}$ (iron oxide) and $1007 \mathrm{~cm}^{-1}$ (Hedenbergite) as illustrated in Fig. 5 .
Table 1. Peaks obtained compared with data from published reference articles: Reference A is Lakshmi Reddy et al. (2015) and Reference B is Cui et al. (2013)

\begin{tabular}{|c|c|c|}
\hline $\begin{array}{l}\text { FTIR Zagami } \\
\left(\mathrm{cm}^{-1}\right) \\
\text { (This work) }\end{array}$ & $\begin{array}{l}\text { Iron oxide FTIR } \\
\left(\mathrm{cm}^{-1}\right)\end{array}$ & $\begin{array}{l}\text { Iron oxide FTIR } \\
\qquad\left(\mathrm{cm}^{-1}\right) \\
\text { (Reference B) }\end{array}$ \\
\hline 3450 & 3445 & 3400 \\
\hline 2927 & 2925 & 2924 \\
\hline 2850 & 2853 & 2850 \\
\hline 1742 & 1746 & - \\
\hline 1632 & 1628 & 1632 \\
\hline 1400 & 1464 & 1453 \\
\hline 1344 & 1384 & 1383 \\
\hline 1050 & 1030 & - \\
\hline 962 & - & - \\
\hline 920 & 913 & - \\
\hline 880 & - & 892 \\
\hline 725 & 798 & 795 \\
\hline 685 & 695 & - \\
\hline 635 & - & 635 \\
\hline 510 & 536 & - \\
\hline
\end{tabular}

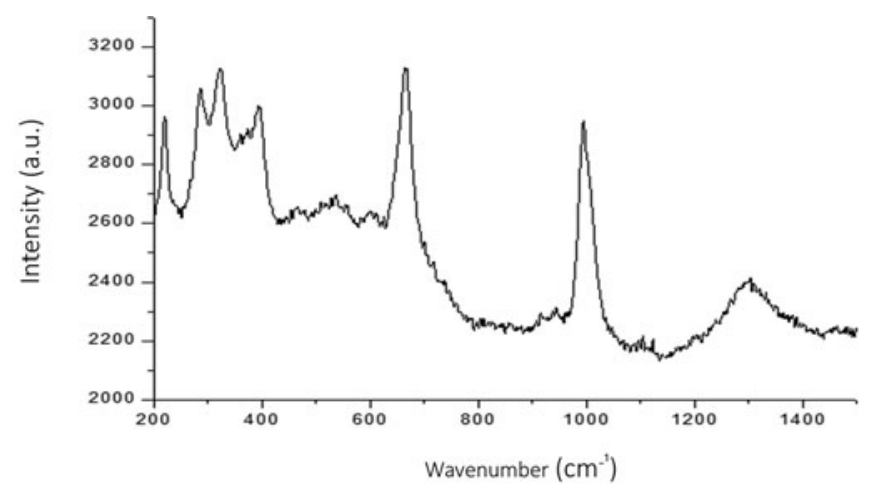

Fig. 4. Raman spectrum obtained from the Zagami meteorite.

Table 2. Data with the peaks obtained and comparison with the data of pure minerals also obtained through Raman dp RRUFF database

\begin{tabular}{lcc}
\hline $\begin{array}{l}\text { Raman Zagami } \\
\left(\mathrm{cm}^{-1}\right)\end{array}$ & $\begin{array}{c}\text { Iron oxide Raman } \\
\left(\mathrm{cm}^{-1}\right)\end{array}$ & $\begin{array}{c}\text { Hedenbergite Raman } \\
\left(\mathrm{cm}^{-1}\right)\end{array}$ \\
(This work) & (Reference RRUFF) & $\begin{array}{c}\text { (Reference RRUFF) } \\
220\end{array}$ \\
\hline 285 & 223 & - \\
\hline 324 & - & 325 \\
\hline 400 & 409 & 395 \\
\hline 666 & $650-670$ & 667 \\
\hline 1006 & 1005 & 1007 \\
\hline 1328 & 1300 & - \\
\hline
\end{tabular}




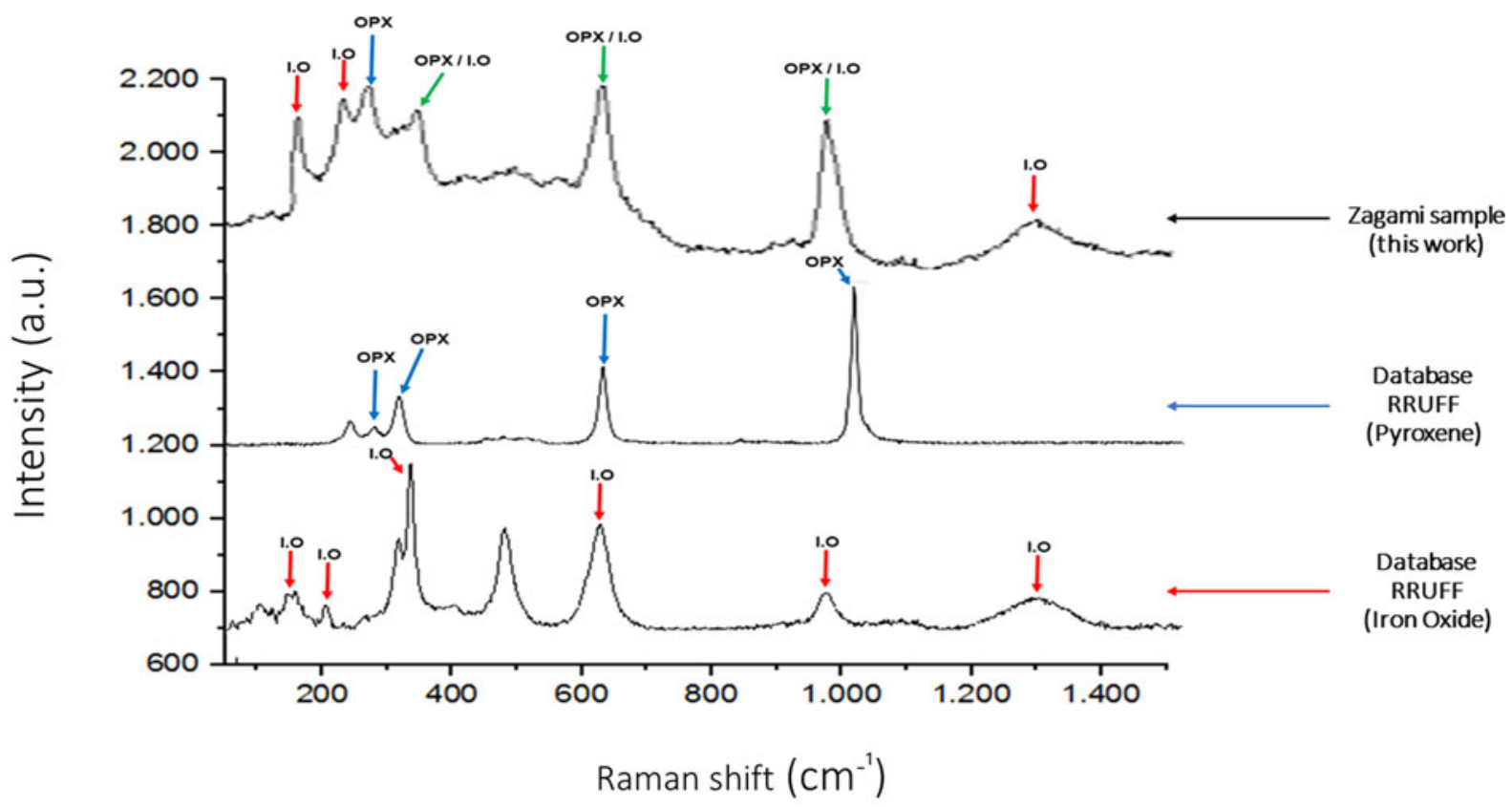

Fig. 5. Comparative spectrum between the result obtained from the Martian meteorite fragment and the pure minerals from the RRUFF database.

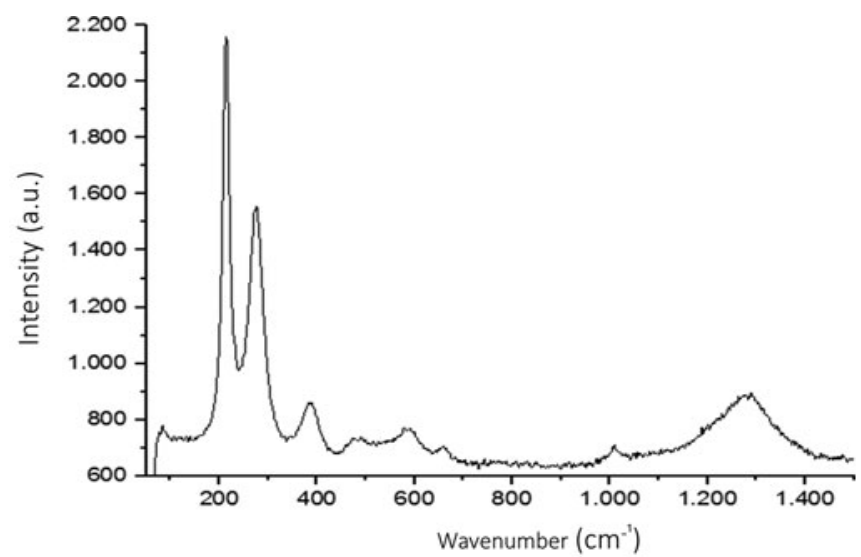

Fig. 6. Second Raman spectrum obtained from the Zagami meteorite.

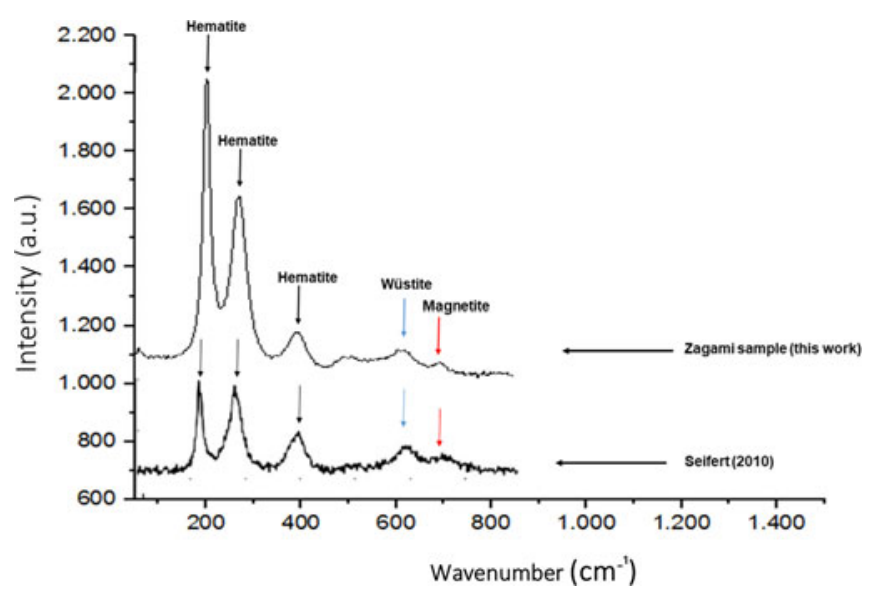

Fig. 7. Comparative spectrum between the result obtained from the Martian meteorite fragment and the spectrum obtained by Seifert et al. (2010).

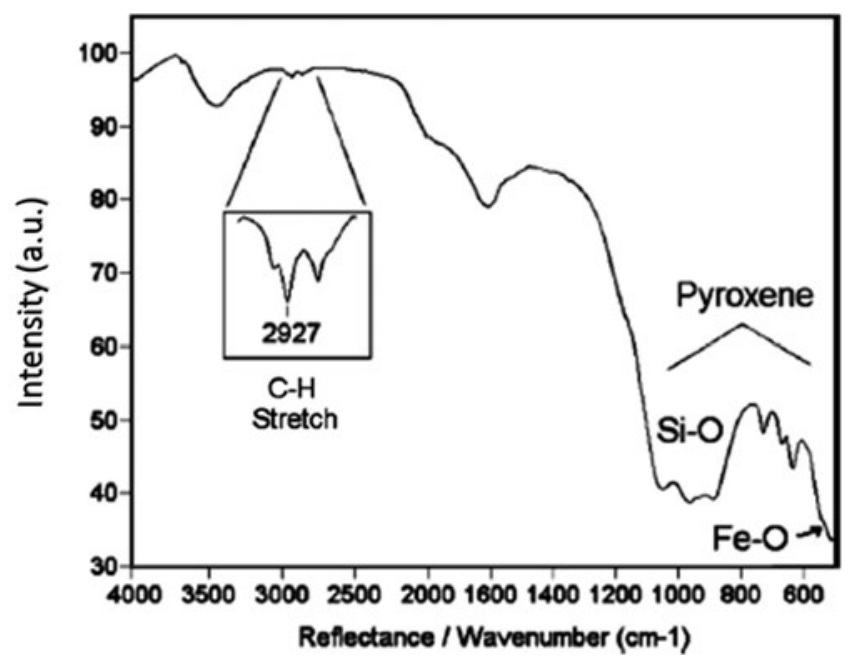

Fig. 8. Image of a spectrum obtained and published by Anderson et al. (2005) when it presents the presence of organic matter in the Martian meteorite Zagami.

In Fig. 6, another Raman spectrum of the Zagami meteorite is presented. Raman spectrum shows the bands in the wavelength region at $1300,600,660,400,275$ and $220 \mathrm{~cm}^{-1}$.

According to Seifert et al. (2010), Hematite can sometimes be found along with the minerals of magnetite and wustite. The Raman spectrum shows in Fig. 7 a composition of the Zagami meteorite sample along with the spectrum obtained by Seifert to demonstrate by comparison the presence of Hematite, Magnetite and Wustite in the Martian meteorite.

\section{Discussion}

Interpreting the results of vibrational techniques

The results presented above show the potential of vibrational techniques for mineral discrimination in a heterogeneous sample, 


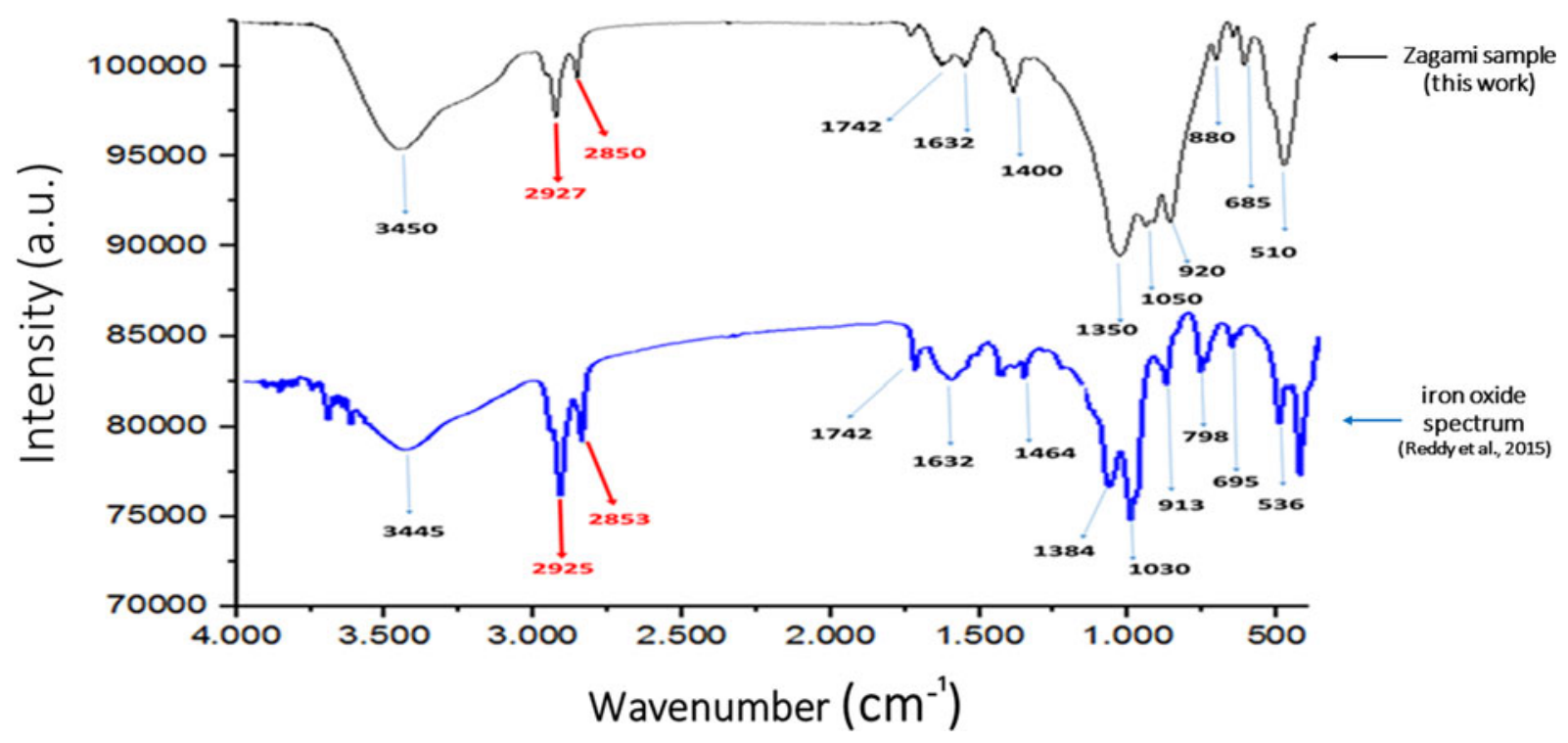

Fig. 9. Comparative spectrum between the result obtained from the Martian meteorite fragment and the spectrum obtained by Lakshmi Reddy et al. (2015).

such as the Martian meteorite Zagami. In the following section, we will discuss in detail the spectral behaviour in our sample, trying to restrict its chemistry and/or structure. The main intention of this work is to analyse the spectral signature obtained by vibrational spectrometry, and compare the result with spectral compositions of the same sample that reported the presence of organic compounds. Some of these studies detected organic compounds; according to Anderson et al. (2005), using FTIR recorded the presence of aliphatic structures in the Zagami meteorite (Fig. 8).

Furthermore, according to Palomba et al. (2006), similar results were obtained confirming this kind of variations across the sample. Still according to the authors, this could be an indication that the organic and water resources in Zagami are due to heterogeneous compounds. However, a possible presence of contaminating material from the time of collection should not be ruled out, even if the authors mentioned above are not in favour of this possibility. Although this work obtained the same band $2927 \mathrm{~cm}^{-1}$, our interpretation is slightly different on the presence of organic compounds. Perhaps you can suggest a second interpretation in relation to this vibrational mode that is not linked to a carbon bond. It is what tries to be exposed next (Fig. 9).

A broad band at $3450 \mathrm{~cm}^{-1}$ in the mineral is assigned to $\mathrm{OH}$ stretching $(v 3)$ of structural hydroxyl groups and a probable existence of water present in the sample. This indicates the possibility of the hydroxyl linkage between octahedral layers. Furthermore, at 1742 and $1632 \mathrm{~cm}^{-1}$ a sharp and intense band is observed, which is due to $\boldsymbol{v} 2$, the asymmetric $\mathrm{OH}$ stretch (deformation mode) of water and is a structural part of the mineral. The sharp band observed at $1400 \mathrm{~cm}^{-1}$ may also be due to $\mathrm{OH}$ stretch of water.

We would like to draw attention specifically to the band at $2920 \mathrm{~cm}^{-1}$. It is possible that this $2927 \mathrm{~cm}^{-1}$ band appeared due to the iron oxide in the sample. However, the interpretation of this band may have been mistakenly attributed to the presence of organic compounds/aliphatic carbon bonds. According to Bikiaris et al. (2000), due to the presence of minerals of iron oxide group, such as hematite and magnetite, the band 2920 and $2850 \mathrm{~cm}^{-1}$ can be assigned to the $\mathrm{FeOOH}$ functional group.
In this functional group, ferrihydrite $\left(\mathrm{Fe}^{\mathrm{III}}(\mathrm{OH})_{3}\right)$ and goethite can be cited.

The maximum sharp absorption band at $1050 \mathrm{~cm}^{-1}$ is a characteristic of $\mathrm{Si}-\mathrm{O}-\mathrm{Fe}$ and $\mathrm{Si}-\mathrm{O}-\mathrm{Si}$ stretching vibration, which plays an important role in the sample, and the band observed at 920 $\mathrm{cm}^{-1}$ is assigned to $\mathrm{OH}$ deformation mode of $\mathrm{Fe}-\mathrm{OH}$. In the low wave number (below $700 \mathrm{~cm}^{-1}$ ) region, iron oxide has the following IR absorptions: Fe-O stretches (lattice modes of FeO6) in the region of $600-700$ and $450-475 \mathrm{~cm}^{-1}$. Accordingly, the two bands observed at 685 and $635 \mathrm{~cm}^{-1}$ are attributed to the Fe-O stretching mode (Vahur et al., 2010). According to Gupta et al. (2014), the band observed at $510 \mathrm{~cm}^{-1}$ corresponds to $\boldsymbol{v} 2$, the deformation mode of $\mathrm{Fe}-\mathrm{O}-\mathrm{Si}$ group. In general, according to Lakshmi Reddy et al. (2015), a band at $1356 \mathrm{~cm}^{-1}$ could be due to overtone of $\boldsymbol{v} 4$ of $\mathrm{SiO}_{4}$ (Table 3).

In addition, another result that corroborates the previous assignments is the complementary Raman data. The presence of iron oxide was detected through Raman, and this mineral would be associated with a possible intergrowth with the ferromagnesian Hedenbergite mineral, belonging to the pyroxene group. Furthermore, other results showed the detection of Hematite, Wustite and Magnetite. In both Raman results, a peculiar band at $1300 \mathrm{~cm}^{-1}$ draws attention. That band also is characterized in meteorites as a D band, which is attributed to structural defects.

In general, according to Brolly et al. (2016), Raman spectroscopy of carbonaceous materials occurs at two wavelength bands. The first, known as 'first-order bands' occur between 1100 and $1800 \mathrm{~cm}^{-1}$ (Tuinstra and Koenig, 1970). The spectra of organic material in this order is characterized by two main bands; the graphitic (G) band, which occurs at $1600 \mathrm{~cm}^{-1}$; and the disordered (D) band, which occurs around at $1300 \mathrm{~cm}^{-1}$, as shown in Fig. 10.

According to Beyssac et al. (2002), D band is a specific frequency of poorly ordered carbon. In general, the band area reduces with stiffening of the aromatic planes and is attributed to in-plane defects, e.g. heteroatoms or structural defects. However, according to Brolly et al. (2016), the hematite 2LO 
Table 3.

\begin{tabular}{lll}
\hline Region $\left(\mathrm{cm}^{-1}\right)$ & Function group & Vibrational mode \\
\hline 3450 & $\mathrm{OH}$ & Stretching \\
\hline 2927 & $\mathrm{FeOOH}$ & \\
\hline 2850 & $\mathrm{FeOOH}$ & \\
\hline 1742 & $\mathrm{OH}$ & Asymmetric stretch \\
\hline 1632 & $\mathrm{OH}$ & Asymmetric stretch \\
\hline 1400 & $\mathrm{OH}$ & Stretch \\
\hline 1344 & $\mathrm{SiO}$ & Overtone \\
\hline 1050 & $\mathrm{Fe}-\mathrm{O}-\mathrm{Si} / \mathrm{Si}-\mathrm{O}-\mathrm{Si}$ & Stretch \\
\hline 962 & $\mathrm{Si}-\mathrm{O}$ & Stretch \\
\hline 920 & $\mathrm{Fe}-\mathrm{OH}$ & OH deformation mode \\
\hline 880 & $\mathrm{Si}-\mathrm{O}$ & Stretch \\
\hline 725 & $\mathrm{Si}-\mathrm{O}$ & Stretch \\
\hline 685 & $\mathrm{Fe}-\mathrm{O}$ & Stretching \\
\hline 635 & Fe-O & Stretching \\
\hline 510 & $\mathrm{Fe}-\mathrm{O}-\mathrm{Si}$ & \\
\hline
\end{tabular}

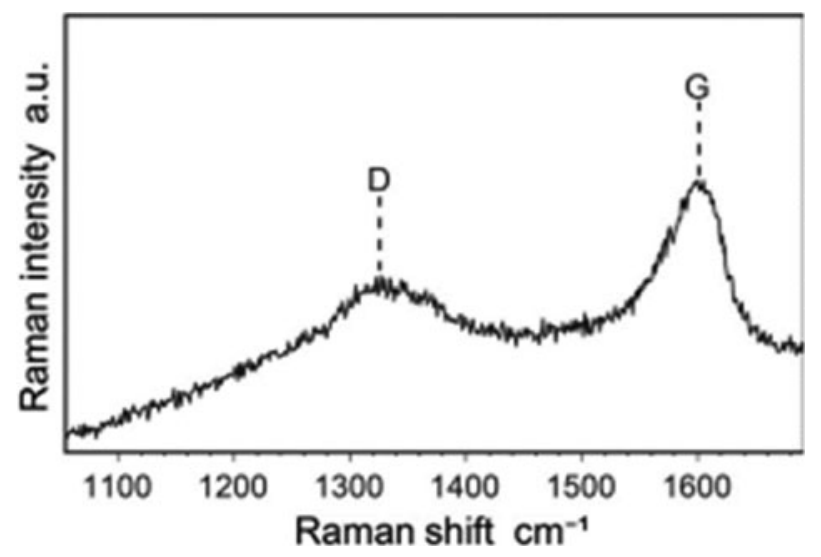

Fig. 10. Illustrative representation of bands D and G.

mode, which is attributed to defects in the hematite lattice, occurs in the same frequency of the carbon D band (Alg mode). Hematite 2LO mode occurs around $1320 \mathrm{~cm}^{-1}$ and is very intense, and overlaps the carbonaceous spectra (Fig. 11). Thus, at $1320 \mathrm{~cm}^{-1}$ it could be misinterpreted as a specialized vibrational mode in the presence of organic matter. However, none of the alternatives can or should be discarded.

\section{Hypotheses and astrobiological implications}

Although the presence of aliphatic structures in a Martian meteorite may seem peculiar, detection is possible and should not be ruled out or considered unfeasible. In this section, some alternative hypotheses will be presented regarding the detected bands whether they come from organic matter or not.

Firstly, it is important to emphasize because the band related to the structural defects of carbon (Band D) and hematite (2LO

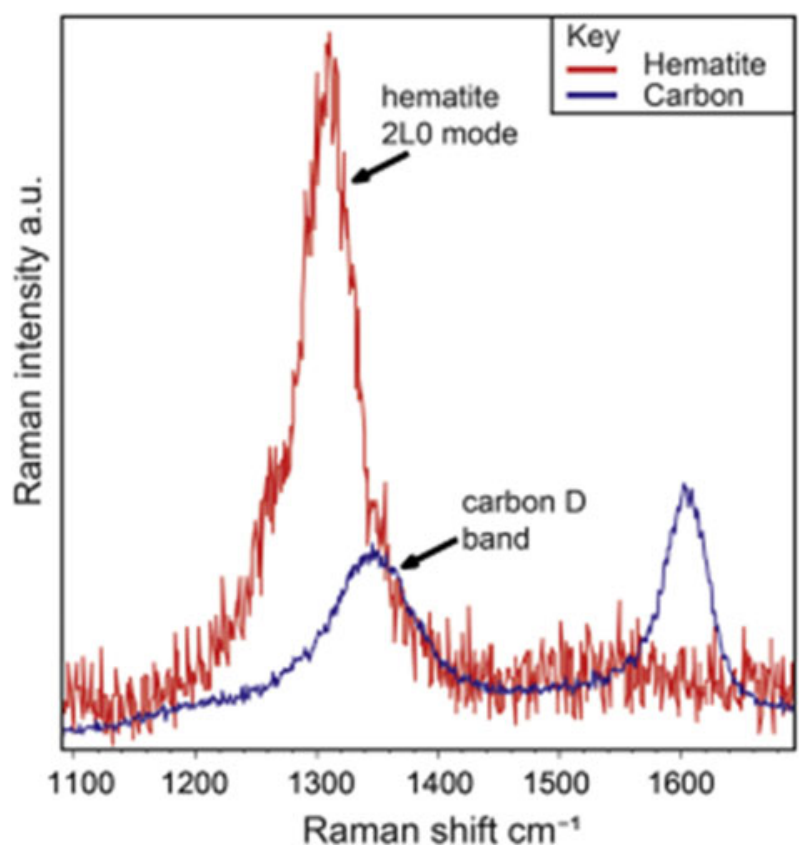

Fig. 11. Illustrative representation of $2 \mathrm{LO}$ mode of hematite.

mode) occur at the same frequency; it is not possible to make a direct and clear distinction about what is actually being detected. However, taking as a premise the results obtained, it is still possible to have relationships between the carbon and the analysed meteorite sample, whether direct or indirect.

Experiments with the mixtures of iron $(\mathrm{Fe})$ minerals and organic matter have already been carried out in order to understand the relationship between both materials (Posth et al., 2013). According to Posth et al. (2013), several paths of magnetite production were observed from the mixture of hydrated iron oxide and $\mathrm{CH}_{2} \mathrm{O}$ (Fig. 12).

However, care must be taken when interpreting magnetite as Banded Iron Formations (BIF), a marker for the primary presence of organic matter. According to Ohmoto (2003), reactions between $\mathrm{Fe}^{(\mathrm{III})}$ and $\mathrm{Fe}^{2+}$ minerals in hydrothermal areas (reactions (1)-(2)) can also form magnetite.

$$
\begin{gathered}
2 \mathrm{Fe}(\mathrm{OH})_{3}+\mathrm{Fe}^{2+} \rightarrow \mathrm{Fe}_{3} \mathrm{O}_{4}+2 \mathrm{H}_{2} \mathrm{O}+2 \mathrm{H}^{+} \\
\mathrm{Fe}_{3} \mathrm{O}_{4}+\mathrm{Fe}^{2+}+\mathrm{H}_{2} \mathrm{O} \rightarrow \mathrm{Fe}_{3} \mathrm{O}_{4}+2 \mathrm{H}^{+}
\end{gathered}
$$

Figure 13 shows three possible trajectories of hematite and magnetite formation formed from mixtures of mineral and organic matter of $\mathrm{Fe}^{(\mathrm{III})}$ in the proportions of high concentration of mixture between organic matter and iron oxide, low concentration of mixture between organic matter and oxide, in addition to no concentration of organic matter and iron oxide.

\section{Conclusion}

It was not possible to totally rule out the possible presence of aliphatic structures in the Martian meteorite. Although this chemical compound is unlikely to be an endogenous component actually present in the Zagami meteorite, there are some 
Fig. 12. Schematic system of magnetite and hematite production from different possible processes by Posth et al. (2013).

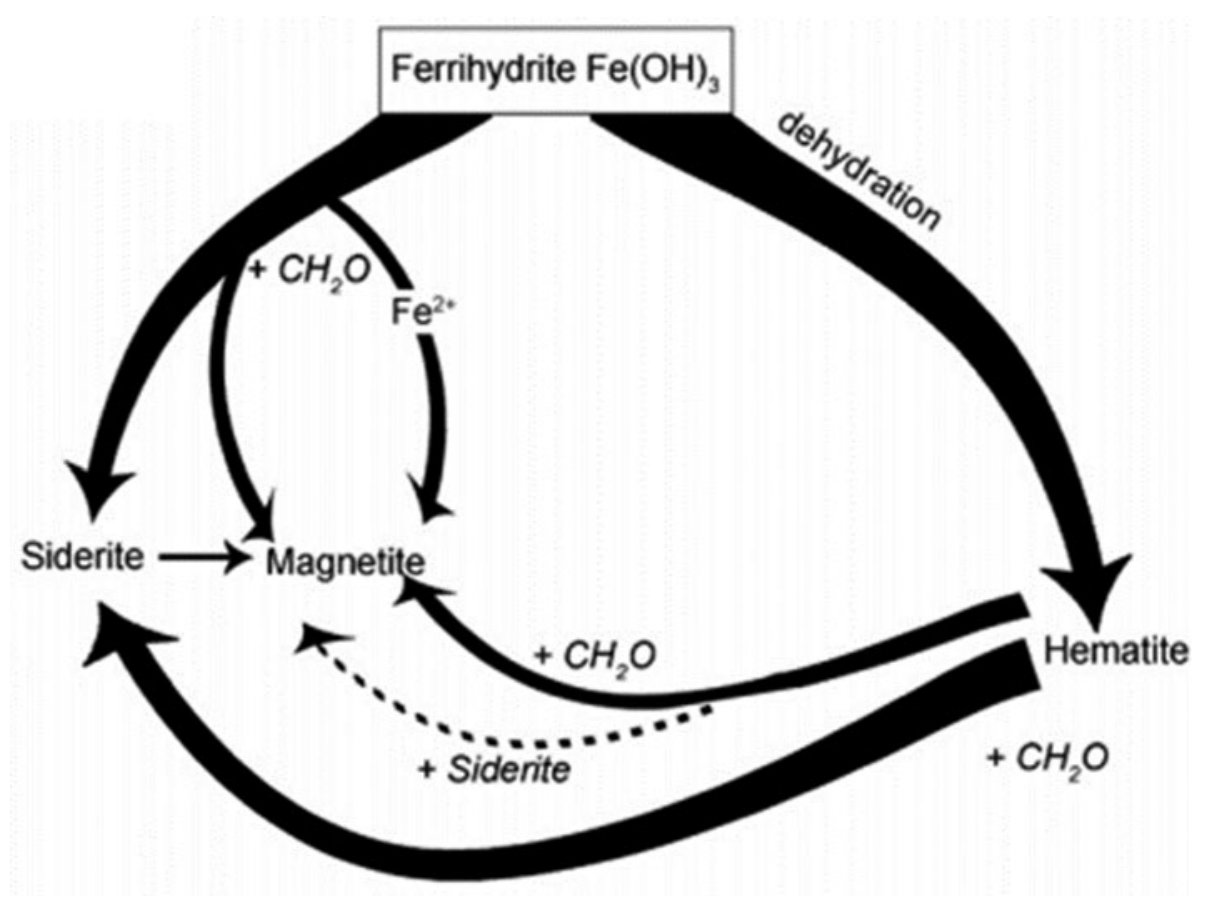

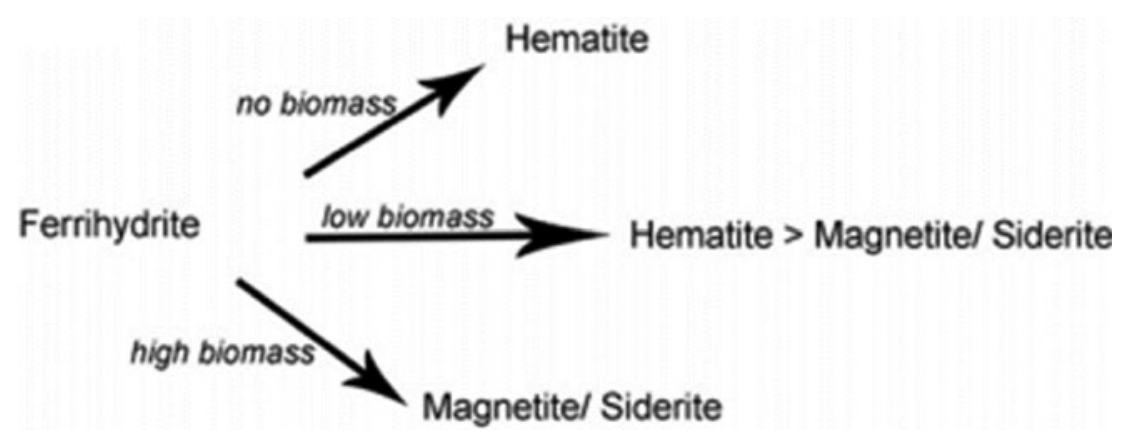

Ferrihydrite
Fig. 13. Representation of three different trajectories for the formation of hematite and magnetite with high, low or without organic matter present in the process of Posth et al. (2013). alternatives. (1) It could refer to possible contamination. Although certain researches that have detected the same results deny this possibility, this cannot be ignored. Although the material has not been manipulated by hand and has been sterilized, the contamination may have occurred during the process of obtaining data, e.g. own interaction of $\mathrm{CO}_{2}$ from the air.

However, this organic compound can be of endogenous origin and not be the result of contamination. This was also a possibility presented in the discussions. In this case, the aliphatic structure could be a contribution of compounds like $\mathrm{CH}_{2} \mathrm{O}$ as a remnant of chemical processes that would have occurred in the past and that can generate these aliphatic compounds.

Finally, the final purpose of this work, based on the results obtained, was to try to present a second interpretative alternative in relation to the previously published data. Based on references from published articles and comparative analyses carried out with the present work, it was possible to obtain another bias and interpretation. The bands 2920 and $2850 \mathrm{~cm}^{-1}$, according to these compared analyses, can be attributed to a possible functional group $\mathrm{FeOOH}$ due to the presence of minerals of the iron oxide group, such as hematite, magnetite, ferrihydrite and goethite.

\section{References}

Anderson MS, Andringa JM, Carlson RW, Conrad P, Hartford W, Shafer M and Hand K (2005) Fourier Transform infrared spectroscopy for Mars science. Review of Scientific Instruments 76, 034101.

Beyssac O, Goffé B, Chopin C and Rouzaud JN (2002) Raman spectra of carbonaceous material in metasediments: a new geothermometer. Journal of Metamorphic Geology 20, 859-871.

Bikiaris D, Daniilia S, Sotiropoulou S, Katsimbiri O, Pavlidou E, Moutsatsou AP and Chryssoulakis Y (2000) Ochre-differentiation through micro-Raman and micro-FTIR spectroscopies: application on wall paintings at Meteora and Mount Athos, Greece. Spectrochimica Acta Part A: Molecular and Biomolecular Spectroscopy 56, 3-18.

Brolly C, Parnell J and Bowden S (2016) Raman Spectroscopy: caution when interpreting organic carbon from oxidising environments. Planetary and Space Science 121, 53-59.

Carr MH and Head III JW (2010) Geologic history of Mars. Earth and Planetary Science Letters 294, 185-203.

Cui H, Liu Y and Ren W (2013) Structure switch between $\alpha$-Fe2O3, $\gamma$-Fe2O3 and $\mathrm{Fe} 3 \mathrm{O} 4$ during the large scale and low temperature sol-gel synthesis of nearly monodispersed iron oxide nanoparticles. Advanced Powder Technology 24, 93-97.

Eugster O, Weigel A and Polnau E (1997) Ejection times of Martian meteorites. Geochimica et Cosmochimica Acta 61, 2749-2757.

Graham AL, Bevan AWB and Hutchinson R (1985) Catalogue of meteorites. Catalogue of meteorites. With special reference to those represented in the 
collection of the British Museum (Natural History). cmws 3, https://ui. adsabs.harvard.edu/abs/1985cmws.book.....G/abstract.

Gupta A, Amitabh V, Kumari B and Mishra B (2014) Defluoridation capability of Jharkhand raw bentonite without transferring neurotoxin aluminium by potash alum of Nalgonda technique. IOSR Journal of Applied Chemistry 7, 1-10.

Jones JH (1986) A discussion of isotopic systematics and mineral zoning in the shergottites: evidence for a 180 my igneous crystallization age. Geochimica et Cosmochimica Acta 50, 969-977.

Lakshmi Reddy S, Reddy G and Ravindra Reddy T (2015) XRD, TEM, EPR, IR and nonlinear optical studies of yellow ochre. Journal of Laser Optics and Photonics 2, 120.

Langenhorst F and Poirier JP (2000) Anatomy of black veins in Zagami: clues to the formation of high-pressure phases. Earth and Planetary Science Letters 184, 37-55.

McCoy TJ, Wadhwa M and Keil K (1999) New lithologies in the Zagami meteorite: evidence for fractional crystallization of a single magma unit on Mars. Geochimica et Cosmochimica Acta 63, 1249-1262.

Nimmo F and Tanaka K (2005) Early crustal evolution of Mars. Annual Review of Earth and Planetary Sciences 33, 133-161.

Nyquist LE, Bogard DD, Shih CY, Greshake A, Stöffler D and Eugster O (2001) Ages and geologic histories of Martian meteorites. In Chronology and Evolution of Mars. Dordrecht: Springer, pp. 105-164.

Ohmoto H (2003) Nonredox transformations of magnetite-hematite in hydrothermal systems. Economic Geology 98, 157-161.

Palomba E, Rotundi A and Colangeli L (2006) Infrared micro-spectroscopy of the martian meteorite Zagami: extraction of individual mineral phase spectra. Icarus 182, 68-79.
Posth NR, Konhauser KO and Kappler A (2013) Microbiological processes in banded iron formation deposition. Sedimentology 60, 1733-1754.

Rolly Connor, Parnell John and Bowden Stephen (2016) Raman spectroscopy: Caution when interpreting organic carbon from oxidising environments. Planetary and space science 121, 53-59

Rolly Connor, Parnell John and Bowden Stephen (2016) Raman spectroscopy: Caution when interpreting organic carbon from oxidising environments. Planetary and space science 121, 53-59

Seifert W, Thomas R, Rhede D and Förster HJ (2010) Origin of coexisting wustite, $\mathrm{Mg}-\mathrm{Fe}$ and REE phosphate minerals in graphite-bearing fluorapatite from the Rumburk granite. European Journal of Mineralogy 22, 495-507.

Shih CY, Nyquist LE, Bogard DD, McKay GA, Wooden JL, Bansal BM and Wiesmann H (1982) Chronology and petrogenesis of young achondrites, Shergotty, Zagami, and ALHA77005: late magmatism on a geologically active planet. Geochimica et Cosmochimica Acta 46, 2323-2344.

Stolper E and McSween Jr HY (1979. Petrology and origin of the shergottite meteorites. Geochimica et Cosmochimica Acta 43, 1475-1498.

Tuinstra F and Koenig JL (1970) Raman spectrum of graphite. The Journal of Chemical Physics 53, 1126-1130.

Vahur S, Teearu A and Leito I (2010) ATR-FT-IR spectroscopy in the region of $550-230 \mathrm{~cm}^{-1}$ for identification of inorganic pigments. Spectrochimica Acta Part A: Molecular and Biomolecular Spectroscopy 75, 1061-1072.

Vickery AM and Melosh HJ (1987) The large crater origin of SNC meteorites. Science (New York, N.Y.) 237, 738-743.

Wang A, Jolliff BL and Haskin LA (1999) Raman Spectroscopic characterization of a Martian SNC meteorite: Zagami. Journal of Geophysical Research: Planets 104, 8509-8519. 